\title{
Construction and Empirical Analysis of Environmental Cost Early-warning Model for Manufacturing Enterprises Based on Fishbone Diagram
}

\author{
Jin Qiu \\ Guangdong University of Science \& Technology, Dongguan, China \\ Email: 610192133@qq.com
}

\begin{abstract}
The deterioration of global ecological environment has caused the issue of environmental protection to be paid increasing attention to, and the importance of establishing and implementing an environmental cost control system has become gradually highlighted for enterprises. Moreover, pre-control is a prerequisite for the environmental cost control system. At present, the link of environmental cost early warning has not been reflected in the current environmental cost control mechanism of enterprises, resulting in some losses of environmental cost arising from insufficient prevention of environmental costs in some enterprises. This paper conducts a preliminary research on the early-warning model of environmental cost, for the purpose of warning enterprises of environmental costs and potential environmental losses under the increasingly prominent contradiction of insufficient water, land, energy and mineral resources caused by economic growth and population growth, thereby seeking for an effective approach to coordinate the economic activities of manufacturing enterprises with the natural environment, and to balance the symbiosis of economic growth, social development and environmental protection.
\end{abstract}

Keywords: Environmental cost, early-warning model, manufacturing enterprises, fishbone diagram.

\section{Outline of Environmental Cost Early-warning Model for Manufacturing Enterprises}

The early-warning model of environmental cost for manufacturing enterprises, an early-warning model environmental loss cost for manufacturing enterprises (especially those with high pollution), is to make use of matrix analysis, ratio analysis, comparative analysis and factor analysis and other analytical methods to analyze and forecast the environmental factors in the production, operation and financial activities of enterprises based on the environmental financial statements, green production plans and other relevant environmental accounting information provided by enterprises, as well as the theories of finance and accounting, statistics, finance, enterprise management and marketing, so as to foresee the potential risk of environmental loss in business management activities, warn the management of enterprises prior to the occurrence of a loss, and urge enterprises to take effective measures to avoid the potential environmental risk evolving into actual loss, thus providing against any potential risk[1]. Moreover, as an important subsystem of enterprise financial early-warning system, the environmental cost early-warning model can also provide reliable basis for enterprises to correct their management direction, improve business decisions and conduct effective allocation of environmental resources. In a word, it is of great significance for enterprises to establish an environmental cost early-warning system, enhance environmental cost management and avoid environmental loss cost in a reasonable and effective manner by carrying out environmental factor analysis and establishing an environmental cost early-warning model[2].

\section{$2 \quad$ Principles of Establishing the Environmental Cost Early-warning Model for Manufacturing Enterprises}

The fundamental function of environmental cost early-warning is to prevent and resolve environmental risks and minimize the loss cost caused by environmental risks as much as possible. In case of signs of 
aggravated environmental risk in an enterprise, the early warning function will send out an early warning signal to remind the management to take measures as soon as possible, find out the causes for the increase in environmental loss costs in a timely manner, and take effective measures actively to improve the potential environmental loss factors in the process of production and operation and resolve environmental risks[3]. Through the environmental cost early-warning system, the causes, solutions and results of disposal of environmental risks can be recorded in detail, and the deficiencies in the existing environmental cost management and green management system of enterprises can be made up for, and post-control will be shifted to pre-control so as to provide against possible risks[4]. In order to improve the efficiency and results of environmental cost early warning for enterprises, the following principles must be adhered to in establishing the environmental cost early-warning model:

1) Principle of practicability: The established environmental cost early-warning model must play a targeted role in forewarning the manufacturing enterprises[5].

2) Principle of systematization: The enterprise must be regarded as an organic whole, and environmental cost early warning should take into account all aspects of green production in manufacturing enterprises.

3) Principle of materiality: It is necessary to integrate the major contradictions and the principal aspects of contradictions in the process of enterprises' environmental cost control, attach importance to the requirement of "cost-benefit" and select moderate indexes for environmental cost early warning.

4) Principle of feedback: Pre-control should be emphasized in environmental cost early warning. Therefore, in the process of constructing environmental cost early-warning model, we should not only rely on the information feedback of environmental accounting, but also concentrate more on the process management of environmental cost, and attempt to overcome the lag of environmental cost information to the full, so as to achieve the real-time feedback of environmental cost information[6].

5) Principle of perspectiveness: As the external macro-environment is constantly changing and the enterprises are growing up, we should insist on the development perspective and consider from a long-term point of view, and the environmental cost early-warning system must be forward-looking, dynamic and adaptable[7].

6) Principle of objective quantification: Environmental cost early warning indexes must be objective and be easily identified, forecast and quantified. In the process of index processing, the levels of iteration must be minimized and the distortion error should be reduced. Furthermore, attention should be paid attention to data mining of environmental cost and optimal stopping point. The mining and utilization of index data should cease at the right moment so as to avoid being excessively complicated or simple.

\section{Empirical Analysis of Establishing the Environmental Cost Early-warning Model}

Enterprises must have their specific functions to establish an environmental cost early-warning mechanism and implement the management of environmental cost early warning, so as to have its own value.

1) Capture function: It can capture the environmental cost information in real time, and the established environmental cost early-warning model can detect potential environmental losses and send out warning signals at any time.

2) Prediction function: Under the control of environmental cost early-warning model, the development trend and ultimate possible results of potential environmental risks can be predicted promptly.

3) Judgment function: The indexes of the environmental cost early warning model should be reasonable and able to judge the crisis degree of environmental factors in real time.

4) Indication function: It can send out an alarm signal in a timely and sensitive way.

5) Tracking, prevention and control functions: It can track the development and change of potential environmental loss factors, analyze the causes of alarms in real time, know how and why there is an alarm, and formulate effective measures to prevent their further deterioration and avoid the occurrence of environmental loss costs.

6) Countermeasure function: It can provide basic countermeasures and methods for alarm events and play a role in assisting in decision-making.

7) Immune function: It can learn from the experience and lessons of competitors in the industry horizontally, record the processing and evaluation results of environmental cost alarm of the enterprise, summarize and accumulate the lessons from the failure of enterprises in the same industry constantly, and 
then help to enhance the ability and effect of financial early warning and the ability to resist environmental risks.

\section{Empirical Analysis of the Environmental Cost Early-warning Model for Manufacturing Enterprises Based on the Fishbone Diagram}

4.1 Target demand analysis of products' environmental cost for manufacturing enterprises - A case study of an electronic product (See Table 1)

Table 1. Analysis of product environmental requirements

\begin{tabular}{|c|c|c|c|c|}
\hline $\begin{array}{l}\text { Environmental } \\
\text { requirement }\end{array}$ & $\begin{array}{l}\text { Green material } \\
\text { design }\end{array}$ & $\begin{array}{l}\text { Green process } \\
\text { design }\end{array}$ & $\begin{array}{l}\text { Green packaging } \\
\text { design }\end{array}$ & $\begin{array}{l}\text { Product recovery } \\
\text { and disposal }\end{array}$ \\
\hline $\begin{array}{l}\text { Subdivision of } \\
\text { products' } \\
\text { environmental } \\
\text { requirements }\end{array}$ & $\begin{array}{l}\text { Naturally decomposed } \\
\text { materials } \\
\text { Non-coil-coated } \\
\text { materials } \\
\text { Minimum processing } \\
\text { pollution } \\
\text { Minimum scrapping } \\
\text { pollution }\end{array}$ & $\begin{array}{l}\text { Save resources } \\
\text { Save energy } \\
\text { Minimum pollution }\end{array}$ & $\begin{array}{l}\text { Green packaging } \\
\text { material } \\
\text { Recycling technology } \\
\text { Packaging structure } \\
\text { optimization } \\
\text { Waste recovery and } \\
\text { disposal }\end{array}$ & $\begin{array}{l}\text { Easy to dismantle the } \\
\text { designed structure } \\
\text { Easy to identify the } \\
\text { reusable components } \\
\text { Easy to maintain the } \\
\text { structural design } \\
\text { Easy to recycle parts } \\
\text { and components }\end{array}$ \\
\hline
\end{tabular}

4.2 Construction of environmental cost early-warning model for manufacturing enterprises based on fishbone diagram

(1) The following steps are taken to establish a fishbone diagram for the early-warning indexes of environmental cost of the product:

1) Define the environmental early-warning target of the product in Table 1;

2) Organize a group of experts to simulate the budget and detect the environmental factors causing potential environmental risks;

3) Draw the diagram;

4) Find out the environmental factors layer by layer, compose the index system and draw it on the fishbone.

Taking the environmental cost early-warning indexes of an electronic product as an example, the fishbone diagram of the environmental cost early-warning factors of the product is drawn, as shown in Figure 1.

(2) Hierarchical construction and weight calculation of environmental cost early-warning model

1) Turn the fishbone diagram in Figure 1 into the hierarchical model of environmental cost early-warning targets, as shown in Figure 2.

2) Establish the environmental factor evaluation matrix (MET matrix) of the environmental cost early-warning model

The establishment of the environmental factor matrix of the early-warning model by means of the MET matrix can not only reflect the environmental protection performance of products, but also save time and reduce costs. It can also be widely used in environmental cost assessment of various types of products.

The MET matrix of environmental factors in the environmental cost early warning model of manufacturing enterprises is shown in Table 2.

The first column of MET matrix of the environmental cost early-warning model consists of five production links and the first line is composed of environmental factors to be evaluated. Each cell in the matrix is composed of several environmental cost evaluation indexes, and the evaluation results are Boolean data (a piece of Boolean data is used to store logical values (Boolean values)). Boolean values are divided into two types of false and true, and the serial number of false is 0 , and the serial number of true is 1 . Both false and true are predefined constant table identifiers, representing logical falsehood and logical truth respectively. 


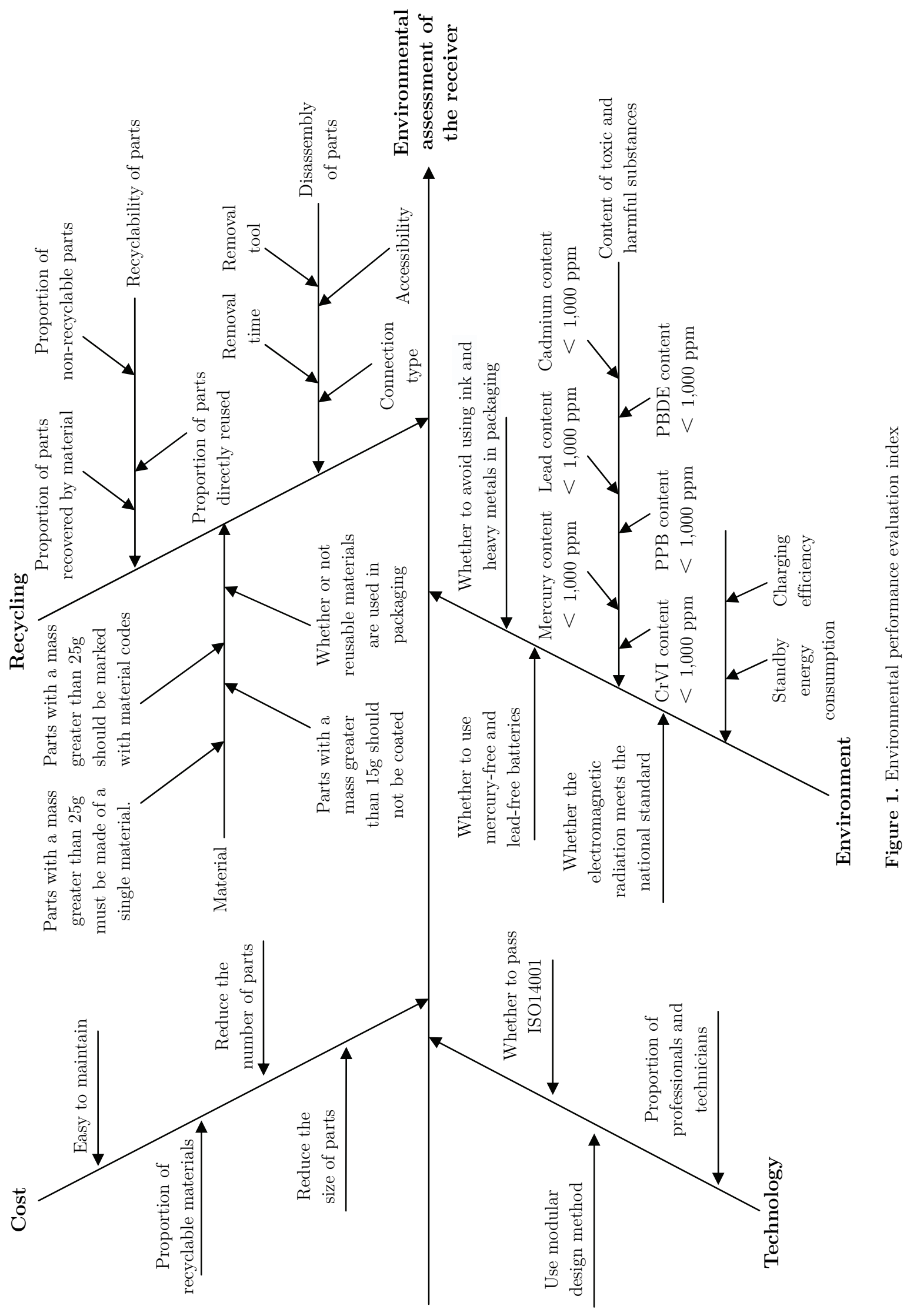




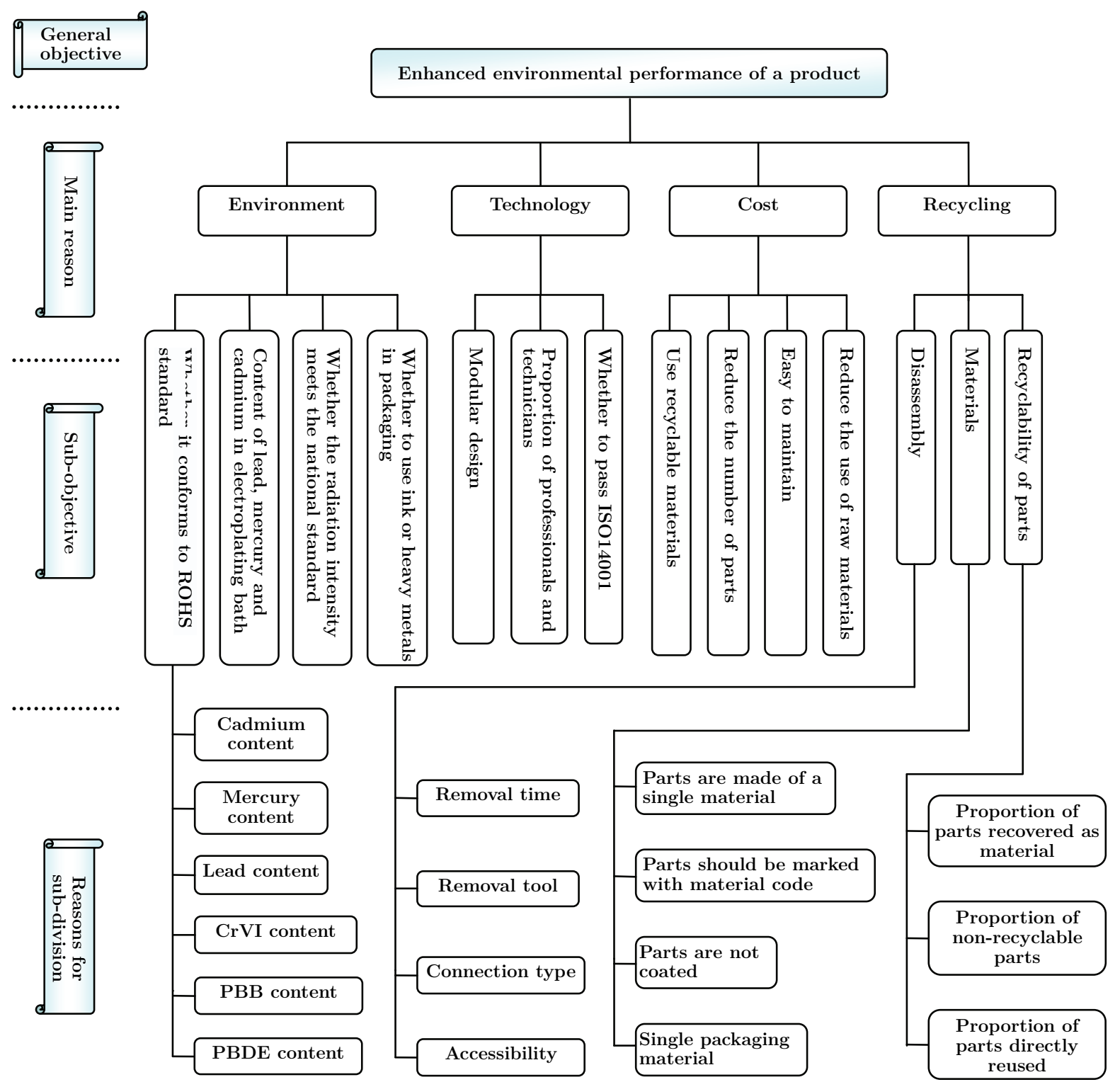

Figure 2. Environmental cost early warning model

Table 2. MET matrix of environmental factors

\begin{tabular}{c|ccccc}
\hline Green index & Recycle & Cost & Technology & Environment & $\begin{array}{c}\text { Index sum (line) } \\
\text { of each stage }\end{array}$ \\
\hline Green material design & $A_{1}$ & $A_{2}$ & $A_{3}$ & $A_{4}$ & $\sum A_{i}$ \\
Green process design & $B_{1}$ & $B_{2}$ & $B_{3}$ & $B_{4}$ & $\sum B_{i}$ \\
Green packaging design & $C_{1}$ & $C_{2}$ & $C_{3}$ & $C_{4}$ & $\sum C_{i}$ \\
Product recycling design & $D_{1}$ & $D_{2}$ & $D_{3}$ & $D_{4}$ & $\sum D_{i}$ \\
Green supply chain design & $E_{1}$ & $E_{2}$ & $E_{3}$ & $E_{4}$ & $\sum E_{i}$ \\
Index sum (row) of each stage & $\sum I_{1}$ & $\sum I_{2}$ & $\sum I_{3}$ & $\sum I_{4}$ & \\
\hline
\end{tabular}


Analysis of letter formula in MET matrix of the environmental cost early-warning model:

Each cell in the matrix represents the environmental performance of the product's environmental cost index in this link. For instance, $A_{2}$ represents the environmental impact or the loss value of environmental cost of the product in green process design.

The sum of figures in a single line represents the environmental cost impact of each production link of the product. For example, $\Sigma B_{i}$ represents the environmental performance of the product in the stage of process design. By comparing $\Sigma A_{i}, \Sigma B_{i}, \Sigma C_{i}, \Sigma D_{i}$ and $\Sigma E_{i}$, the links of environmentally friendly process to be improved can be determined.

The sum of figures in a single column represents the total impact of the production links on the environmental factors of the product. For instance, $\Sigma I_{1}$ represents the recyclability of the product in the whole production process. By comparing $\Sigma I_{1}, \Sigma I_{2}, \Sigma I_{3}$ and $\Sigma I_{4}$, the environmental cost factors to be improved can be found.

3) AHP (Analytical Hierarchy Process) model and determination of index weight

In this paper, fuzzy analytic hierarchy process (FAHP) was used to calculate the weights and build the weighted MET matrix of the environmental cost early-warning model. It is assumed that the element A in the upper layer is the same as the elements $f_{1}, f_{2}, \ldots, f_{n}$, the fuzzy judgment matrix $F$ can be expressed as the matrix:

\begin{tabular}{ccccc}
$A$ & $f_{1}$ & $f_{2}$ & & \\
\hdashline$f_{1}$ & $f_{11}$ & $f_{12}$ & $\ldots$ & $f_{n}$ \\
$f_{2}$ & $f_{21}$ & $f_{22}$ & $\ldots$ & $f_{1 n}$ \\
$\ldots$ & $\ldots$ & $\ldots$ & $\ldots$ & $\ldots$ \\
$f_{n}$ & $f_{n 1}$ & $f_{n 2}$ & $f_{n 3}$ & $f_{n n}$
\end{tabular}

$f_{i j}$ was scaled as shown in Table 3 , and the weight formula in the matrix is as follows:

$$
M_{i}=\frac{\sum_{j=0}^{n} f_{i j}-0.5 n+a}{a n}(0 \leq a \leq 0.5)
$$

In the formula, $M_{i}$ represents the weight value of each index, and $f_{i j}$ represents the relative importance of each index.

Table 3. 0.1 0.9 scale

\begin{tabular}{|c|c|c|}
\hline Scale & Definition & Descriptions \\
\hline $0.1 \sim 0.4$ & Converse comparison & $\begin{array}{l}\text { The element } b_{i j} \text { is obtained by comparing the element } \\
b_{i} \text { and the element } b_{j} \text {, and then it is judged that } \\
b_{j i}=1-b_{i j} \text { by comparing the element } b_{j} \text { and the } \\
\text { element } b_{i} \text {. }\end{array}$ \\
\hline 0.5 & Equally important & Comparing the two elements, they are equally important. \\
\hline 0.6 & Slightly important & $\begin{array}{l}\text { Comparing the two elements, one element is slightly more } \\
\text { important than the other. }\end{array}$ \\
\hline 0.7 & Obviously more important & $\begin{array}{l}\text { Comparing the two elements, one element is obviously } \\
\text { more important than the other. }\end{array}$ \\
\hline 0.8 & Much more important & $\begin{array}{l}\text { Comparing the two elements, one element is much more } \\
\text { important than the other. }\end{array}$ \\
\hline 0.9 & Extremely important & $\begin{array}{l}\text { Comparing the two elements, one element is extremely } \\
\text { more important than the other. }\end{array}$ \\
\hline
\end{tabular}

Empirical analysis: After building a complete hierarchical model, the company organized experts to compare the causes of each layer, constructs the matrix $\mathrm{F}$ of the product environmental early warning model, and calculates the weight of each layer with the formula. The final results are shown in Figure 4. The weights of the five stages of the production process are calculated to be $0.3,0.37,0.16,0.09$ and 0.08 , respectively. 


\subsection{Evaluation criteria of environmental cost early-warning indexes}

The scoring range of environmental cost early-warning indexes is $0,1,3$ and 5 . If the toxic substance content in the environmental cost early-warning indexes is formulated according to the RoHS Directive of the European Union, the evaluation criteria can be improved according to the existing level of the enterprise as the enterprise meets the RoHS Directive. For example, the PBB content that is no more than $400 \mathrm{ppm}$ is " 5 ", the PBB content that is more than 400ppm but no more than 700ppm is " 3 ", and the PBB content that is more than 700ppm but no more than 900ppm is "1", and the PBB content that is more than $900 \mathrm{ppm}$ is " $0 "$ ".

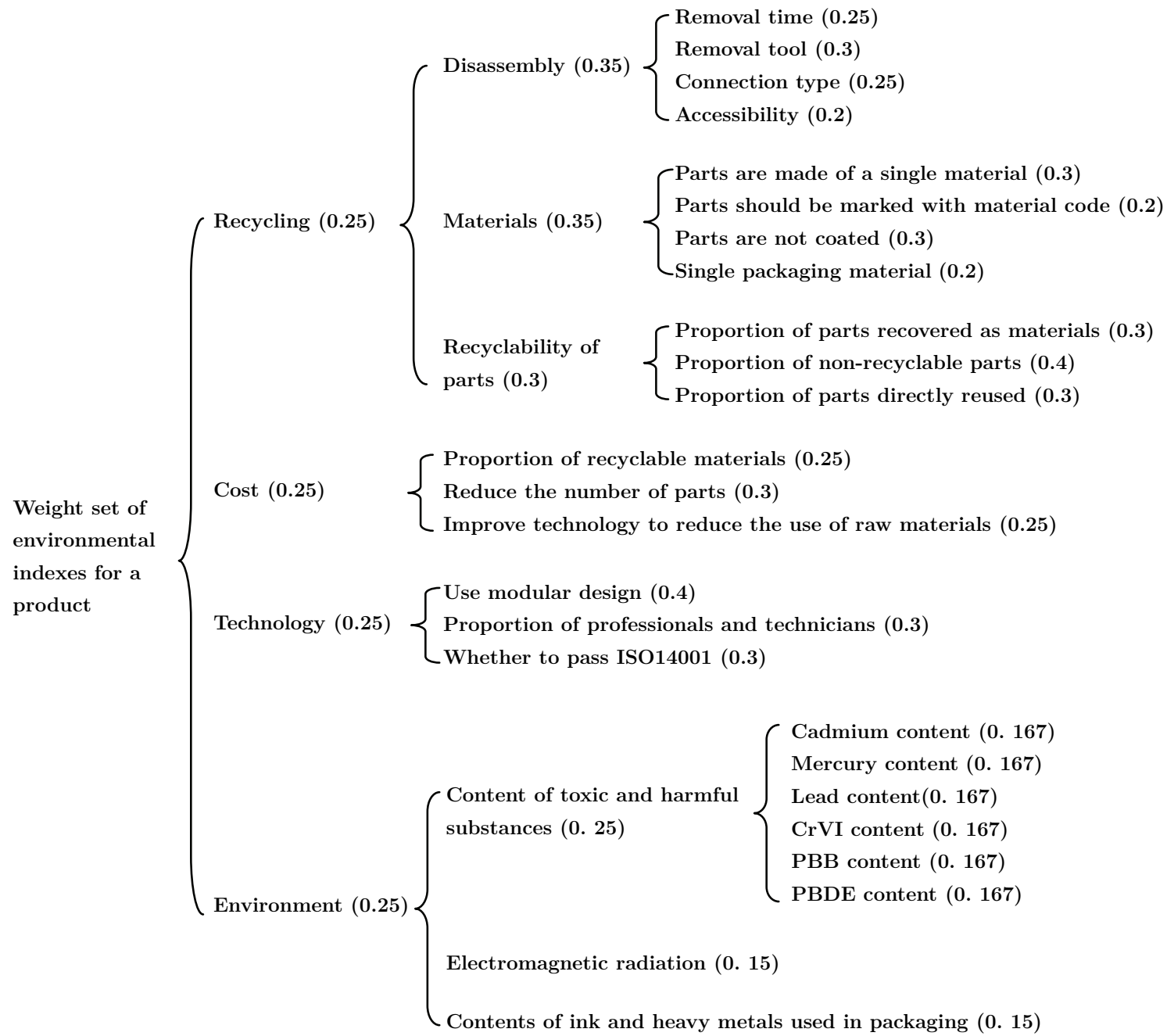

Figure 3. Environmental index weight

\subsection{Evaluation results}

Each environmental cost early-warning index was scored according to the established criteria, the comprehensive weight of each index was calculated and the matrix of environmental cost early-warning model was established as shown in Table 4.

Empirical analysis: The results of the evaluation in the above table (Table 4) show the result of early warning that the product takes a higher environmental cost with poor environmental performance. The sequence is that L3 > L2 > L4 > L1 > L5, which indicates that the product is designed with insufficient recyclable materials, thus making it difficult to recycle and reuse the product that has been discarded, so 
that the environmental performance of the product should be improved by means of substitution technology of toxic and harmful substances and improvement of product disassembly. The sequence of the environmental cost indexes of the product is $\mathrm{T}>\mathrm{C}>\mathrm{E}>\mathrm{R}$, which indicates that the product has lower environmental index and recyclability index and that the product lays particular emphasis on function, shape and other aspects, resulting in its complex structure and difficulty in disassembling and recycling after abandonment. The data in the early-warning model reflects that the product has a minimum environmental cost index in the stage of scrapping. It can be analyzed that the reason is that the enterprise does not have a relatively perfect product recycling system, and that private recyclers usually dispose of the waste products in their hands by means of non-environmental recovery methods such as incineration and chemical treatment, which cause environmental pollution such as water and atmosphere, and low reuse rate of resources, and then a waste of resources. The improvement measures of product design by ecological design can be based on the results of the data of the environmental cost early-warning model, and the sequence of the indexes to be improved can refer to the comprehensive importance of index values, as the smaller the figure is, the greater the impact will be. It can be proved from the empirical analysis that the environmental cost early-warning model is effective in estimating the environmental cost index of the product and warning the environmental loss of the enterprise.

Table 4. Results of environmental early warning assessment for a product

\begin{tabular}{|c|c|c|c|c|c|}
\hline $\begin{array}{ll}\text { Lifecycle } & \text { Green index } \\
\end{array}$ & Recycle & Cost & Technology & Environment & $\begin{array}{l}\text { Index sum (line) } \\
\text { of each stage }\end{array}$ \\
\hline Green material design $L_{1}$ & 0.23 & 0.36 & 0.62 & 0.27 & 0.41 \\
\hline Green process design $L_{2}$ & 0.21 & 0.49 & 0.62 & 0.24 & 0.37 \\
\hline Green packaging design $L_{3}$ & 0.25 & 0.51 & 0.66 & 0.33 & 0.41 \\
\hline Product recycling design $\mathrm{L}_{4}$ & 0.19 & 0.38 & 0.60 & 0.30 & 0.43 \\
\hline Green supply chain design $\mathrm{L}_{5}$ & 0.32 & 0.31 & 0.51 & 0.21 & 0.30 \\
\hline Index sum (row) of each stage & 0.24 & 0.41 & 0.60 & 0.27 & - \\
\hline
\end{tabular}

\section{Conclusion}

This paper establishes the environmental cost early-warning model of enterprises based on the fishbone diagram, MET matrix and other theories. It can be seen that the model has a moderate application effect and practicability through the early warning analysis of environmental cost of an electronic product. Especially for manufacturing enterprises, it is the core link to control their environmental costs. However, the research on enterprises' environmental costs needs to be further deepened due to the ambiguity, complexity and difficulty in measuring environmental costs of high-polluting enterprises. Moreover, the research on its early-warning model or even early-warning system needs to be further advanced.

\section{References}

1. CICA. Environmental costs and liabilities [M].Accounting and Financial Reporting Issues (1998 - 2010).1998

2. A.D. Chandler. The United States: Evolution of Enterprise //P. Mathias, M.M. Postan. The Cambridge Economic History of Europe, Vol.VII, the Industrial Economies: Capital, Labor and Enterprise, Combridge UP, 1998: 70-133.

3. Wang Yuetang. Management of Environment Costs: pre-programming Methods and its Enlightenment [J].Accounting Research, 2011 (3): 54-57

4. Wang Liyan. Environmental Cost Accounting and Environmental Accounting System [J]. Economic Science, 2010 (6): 55-59

5. Mao Hongtao. Discussion on the Application of Environmental Cost in Enterprises [J]. Accounting Research, 2011 (6): $56-59$

6. Bazaml, navas-alemanl. Up grading in Global and National Value Chains: Recent Challenges and Opportunities for the Sinos Valley Foot wear Cluster, Brazilin Schmitz, H.(ed.), Local Enterprises in the Global Economy: Issues of Governance and upgrading [M]. Cheltenham: Edward Elgar, 2011.

7. Kevin A. Kitzman. Environmental cost accounting for improved environmental decision-making $[\mathrm{J}]$. Pollution Engineering, Troy 2011,12:45 49 